\title{
Comparison of Glasgow Coma Scale and Full Outline of Unresponsiveness (Four) Score: A Prospective Study
}

\author{
Yesim Serife BAYRAKTAR ${ }^{1}$, Mert SAHINOGLU², Faruk CICEKCI ${ }^{1}$, Inci KARA ${ }^{1}$, Hakan KARABAGLI ${ }^{2}$, \\ Ates DUMAN'1, Jale Bengi CELIK ${ }^{1}$ \\ ${ }^{1}$ Selcuk University, School of Medicine, Department of Anesthesiology and Reanimation, Konya, Turkey \\ ${ }^{2}$ Selcuk University, School of Medicine, Department of Neurosurgery, Konya, Turkey \\ This study has been presented at the $32^{\text {nd }}$ Scientific Congress of Turkish Neurosurgical Society between 20 and 24 April 2018 at Antalya, Turkey
}

Corresponding author: Yesim Serife BAYRAKTAR yesimbayraktar1983@hotmail.com

\section{ABSTRACT}

AIM: To assess reliability by comparing the Full Outline of Unresponsiveness (FOUR) scores and Glasgow Coma Scale (GCS) values assigned by specialists from two different fields to patients in the Anesthesiology and Reanimation and Neurosurgery intensive care units.

MATERIAL and METHODS: This study was conducted between March 2017 and June 2017 at Selcuk University Faculty of Medicine, Departments of Anesthesiology and Reanimation and Neurosurgery. Seventy-nine patients aged 18-65 years who were treated for at least 24 hours in the intensive care unit were independently assessed by two raters, an anesthesiologist and a neurosurgeon, using FOUR and GCS. The Kolmogorov-Smirnov normality test was applied for continuous variables, and SPSS 20.0 version software was used for data analyses.

RESULTS: There were no significant differences between FOUR scores and GCS values given by the two raters. The mortality rate among patients with low scores on both FOUR and GCS was higher than the hospital mortality rate.

CONCLUSION: Considering that FOUR score allows a more detailed neurological evaluation than GCS, and our findings suggest that FOUR score is more useful for patients who are unconscious or dependent on mechanical ventilation.

KEYWORDS: Consciousness, Full outline of unresponsiveness, FOUR, Glasgow coma scale, GCS

\section{INTRODUCTION}

S coring systems are often used in intensive care settings to assess level of consciousness $(6,10)$. Scales were developed to allow health professionals to describe the general condition, neurological status, and cardiopulmonary status of patients to one another in a succinct and standard way $(2,5,9,10)$. Of these, the Glasgow Coma Scale (GCS) is the most commonly used $(3,4,8,9)$. However, the GCS has several disadvantages. Its use is limited when verbal responses cannot be assessed, especially in intubated and aphasic patients, brain stem reflexes are not incorporated in the scale, and it does not factor in the patient's respiratory pattern (3). Early changes in consciousness associated with deviations in respiratory pattern and brain stem reflexes may not be recognized. Therefore, in 2005 Wijdicks et al. developed the Full Outline of Unresponsiveness (FOUR) as a modification of the GCS (11). Because this scale must also be understood correctly and applied as accurately as possible in Turkey, Orken et al. conducted a reliability study on the Turkish version of the FOUR score in 2010 (8). These scales are a key tool in modifying interventions and treatment plans, particularly for unconscious patients, and scales are user-dependent to some degree. For this reason, comparative
Yesim Serife BAYRAKTAR (D): 0000-0001-5156-7064 Mert SAHINOGLU

Faruk $\mathrm{CICEKCl}$
Inci KARA

(1) : 0000-0001-6546-4277

(1) : $0000-0003-0633-8304$

(10) : 0000-0002-3248-0745
Hakan KARABAGLI (1): 0000-0002-1184-3965

Ates DUMAN (1): 0000-0003-0394-2485
Jale Bengi CELIK (1) : 0000-0003-2167-9967 
studies have been conducted among health workers applying these scales in order to evaluate the reliability of FOUR and GCS $(2,5,8-10,12)$. The purpose of the present study was to assess reliability by comparing the FOUR score and GCS values assigned by specialists from two different fields to patients in an Anesthesiology and Reanimation Intensive Care Unit (ARICU) and a Neurosurgery Intensive Care Unit (NICU).

\section{MATERIAL and METHODS}

The GCS includes three main categories: eye response, verbal response, and motor response. These category scores are summed for a total score ranging from 3 to 15 . The FOUR score, developed as an alternative to GCS, has four main components that evaluate eye response (G4), motor response (M4), brain stem reflexes (B4), and respiration (S4). The simpler scoring of FOUR is easier to remember than the GCS, which has 3 components of eye response (G4), motor response (M6), and verbal response (S5) (Figure 1). Each category is scored from 0 to 4 and the patient can score $0-16$ in total.

\section{Study Design and Sampling}

This study was conducted between March 2017 and June 2017 at Selçuk University Faculty of Medicine, Departments of Anesthesiology and Reanimation and Neurosurgery, with approval of the Observational Ethics Committee (Ref no: 2017/66). Patients aged 18-65 years who were treated for at least 24 hours in the intensive care unit and did not receive sedation were included in the study. Patients under 18 years or over 65 years of age, those under sedation, and those who did not survive for 24 hours in intensive care were excluded from the study.

Throughout the 3-month study period, the consciousness and coma levels of 79 patients in the ARICU and NICU were assessed using FOUR and GCS by an anesthesiologist (Group A) and a neurosurgeon (Group B).

\section{Data Collection}

The patients' consciousness and coma level were assessed with GCS and FOUR. Demographic data of the patients were also collected.Two different practitioners who were unaware of each other both scored each patient within the same time frame. GCS and FOUR scoring were performed within the first 24 hours of the patients' admission to the intensive care units or after the effects of the sedation and muscle relaxant medication has subsided. Each rater assessed patients in both the ARICU and NICU.

\section{Statistical Analysis}

Statistical Package for the Social Sciences (SPSS) version 20.0 software was used for data analyses. Descriptive statistics were calculated for continuous and categorical variables and presented in tables. Continuous variables were expressed as mean \pm standard deviation; categorical variables were expressed in frequency and percentage. The KolmogorovSmirnov normality test was applied for continuous variables. One-way analysis of variance (ANOVA) was used for withingroup comparisons of normally distributed variables, and Tukey's honest significant difference (HSD) test was used for

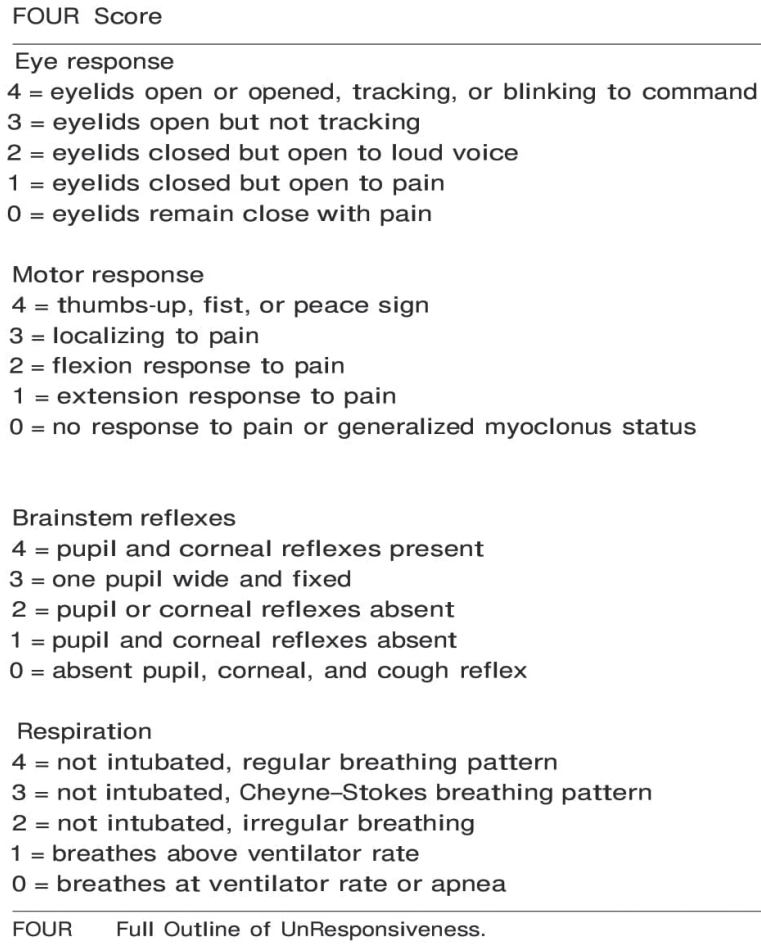

\section{Glasgow Coma Scale}

Eye response

4 = eyes open spotaneously

3 = eye opening to verbal comcommand

2 = eye opening to pain

$1=$ no eye opening

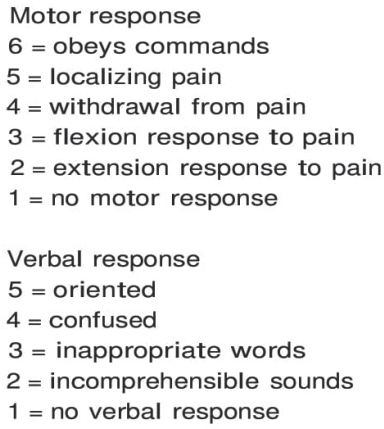


paired comparisons. Kruskal-Wallis variance analysis was used for numerical variables that did not fit normal distribution. $P$ values less than 0.05 were accepted as statistically significant.

\section{RESULTS}

Seventy-nine patients (48 males, 31 females) were enrolled in the study between March 1, 2017 and June 1, 2017. Mean age of the patients was $52.49 \pm 13.49$ years. The patients' diagnoses included ischemic and hemorrhagic stroke $(n=27,34.1 \%)$, pulmonary and cardiac arrest $(n=28,35.4 \%)$, multitrauma $(n=12,15.1 \%)$, sepsis $(n=4,5 \%)$, and other $(n=8$, 10.1\%) (Table I).

Sociodemographic data of the patients and comparison of the FOUR and GCS scores of both groups are shown in Table II. Of the 79 patients in the study, 49.4\% $(n=39)$ were intubated and using mechanical ventilation, 25.3\% $(n=20)$ were tracheotomized and breathing spontaneously or using mechanical ventilation. Assessment of patients in ICU was performed on day 1 at $11.4 \%(n=9)$, on day 2 in $20.3 \%(n=16)$, on day 3 in $17.7 \%(n=14)$, on day 4 in $10.1 \%(n=8)$, on day 5 in $16.5 \%(n=13)$, on day 6 in $20.3 \%(n=16)$ and on day 7 in $3.8 \%$ $(n=3)$. The mortality rate was $35.4 \%(n=28)$.

Table I: Diagnosis of the Patients in the Study

\begin{tabular}{lc}
\hline Diagnosis & $\mathbf{n}(\%)$ \\
\hline Ischemic and hemorrhagic stroke & $27(34.1)$ \\
\hline Pulmonary and cardiac arrest & $28(35.4)$ \\
\hline Multitrauma & $12(15.1)$ \\
\hline Sepsis & $4(5)$ \\
\hline Other & $8(10)$ \\
\hline Total & $79(100)$ \\
\hline
\end{tabular}

The mortality rate among patients with low scores on both FOUR and GCS was higher than the hospital mortality rate.

There were no statistically significant differences between the FOUR scores in Group A and Group B in terms of the eye, motor, brain stem reflex, or respiratory components $(p=0.604$, $\mathrm{p}=0.564, \mathrm{p}=0.140, \mathrm{p}=0.299$ ).

There were also no statistically significant differences between Group A and Group B in terms of GCS eye, motor, and verbal parameters $(p=0.319, p=0.873, p=0.705)$.

Within-group comparisons revealed no significant differences in FOUR and GCS scores in each group $(p=0.05)$.

\section{DISCUSSION}

Clinical evaluation of consciousness is the most fundamental and crucial component of the neurological examination (10). It is considered important for reducing mistakes when evaluating patients in intensive care units, and enables a more accurate assessment. The FOUR scale is as easy to apply as the GCS, which is simple and currently the most widely used scale for assessing consciousness (9).

Disadvantages of the GCS include inability to assess the verbal responses of intubated and aphasic patients, and the fact that it does not incorporate the evaluation of brain stem reflexes or respiratory patterns $(6,7)$. Therefore, early changes in consciousness due to deviations in respiratory pattern and brain stem reflexes may be overlooked. These deficiencies can lead to errors in judgment concerning a patient's state of consciousness, level of recovery from coma, and brain death (8). The respiratory parameters of FOUR enable clinicians to assess whether intubated or tracheotomized patients supported with mechanical ventilation are apneic or are breathing at the ventilator rate. This and the absence of pupil, corneal, and gag reflexes in the brain stem component provides valuable information in terms of brain death. In this respect, FOUR is superior to GCS in alerting clinicians to early

Table II: Sociodemographic Data of the Patients and Comparison of the FOUR and GCS Scores of both Groups

\begin{tabular}{|c|c|c|c|}
\hline $\begin{array}{l}\text { Characteristic } \\
\text { Age (years) }\end{array}$ & \multicolumn{3}{|c|}{ Value (mean \pm standard deviation) } \\
\hline Length of Hospital stay (days) & \multicolumn{3}{|c|}{$8.41 \pm 3.76$} \\
\hline Scoring System & Group A & Group B & $\mathbf{p}$ \\
\hline \multicolumn{4}{|l|}{ FOUR } \\
\hline Brain Stem Reflexes & $3.21 \pm 1.42$ & $3.32 \pm 1.23$ & .140 \\
\hline Respiratory & $2.05 \pm 1.55$ & $1.96 \pm 1.46$ & .299 \\
\hline Total & $9.76 \pm 4.69$ & $9.62 \pm 4.58$ & .525 \\
\hline \multicolumn{4}{|l|}{ GCS } \\
\hline Eye & $2.65 \pm 1.27$ & $2.71 \pm 1.21$ & .319 \\
\hline
\end{tabular}


signs of brain death. On the other hand, the disadvantage of the FOUR score is that it does not test all of the behavioral criteria necessary to diagnose minimally conscious state.

These scales are essential for adapting interventions and treatment plans, especially with unconscious patients, and scales are partially user-dependent. For this reason, numerous comparative studies have evaluated the reliability of FOUR and GCS among healthcare personnel $(2,5,8-10,12)$. The opinion that the FOUR score can be used instead of GCS is supported $(7,8)$. Jalali and Rezaei found that FOUR was comparable to GCS in predicting mortality and functional and cognitive status at discharge in patients with traumatic brain injury in intensive care (2). Because FOUR score provides more neurological detail than GCS, it is a more valid predictor of outcome (7).

Wijdicks et al. reported that the incorporation of brainstem and respiratory parameters made the FOUR scale a better prognostic indicator of mortality than the GCS (11). However, many other studies comparing FOUR and GCS have reported obtaining similar results with the two scales. Eken et al. determined that FOUR score was not superior to GCS in patients presenting to the emergency department with altered level of consciousness (1). Various studies comparing GCS and FOUR scores yielded high inter-observer agreement and correlation coefficients $(8,9)$. In the present study, both the FOUR and GCS scores of patients in each of the two intensive care units were similar between the two observers, an anesthesiologist and a neurosurgeon. Considering the advantages of FOUR, the fact that these scores yielded similar results when applied by two different specialists suggests that FOUR is a more advantageous tool for patient evaluation.

This study has certain limitations. Firstly, the study was conducted in two intensive care units within a single center. Conducting assessments in multiple centers and more intensive care units would allow a more robust evaluation. Secondly, our study only included specialists in surgical anesthesia and neurosurgery. Including assessments by internal medicine specialists may lead to a different result.

\section{CONCLUSION}

There are currently multiple scores used to determine the prognosis of patients in intensive care units. However, a scoring system should be simple, reliable, and predictive of morbidity and mortality.

Our findings of consistency between scores given by two different practitioners to the same patient demonstrate the ease of application of the FOUR and GCS. However, due to the different categories of FOUR score, it is more effective in evaluating patients who are unconscious and dependent on mechanical ventilation. Prospective studies with larger cohorts of patients treated in various intensive care units for longer durations are needed to evaluate whether the application of these scales influences functional and cognitive outcomes.

\section{REFERENCES}

1. Eken C, Kartal M, Bacanli A, Eray O: Comparison of the full outline of unresponsiveness score coma scale and the glasgow coma scale in an emergency setting population. Eur J Emerg Med 16(1):29-36, 2009

2. Jalali R, Rezaei M: A comparison of the Glasgow coma scale score with full outline of unresponsiveness scale to predict patients' traumatic brain injury outcomes in intensive care units. Crit Care Res Pract 2014:289803,2014

3. Karabıyık L: Intensive care scoring systems. Turkish Journal of Intensive Care Medicine 9(3):129-143, 2010

4. Khanal K, Bhandari SS, Shrestha N, Acharya SP, Marhatta MN: Comparision of outcome pretictions by the Glasgow coma scale and the fulloutline of UnResponsiveness score in the neurological and the neurosurgical patients in the Intensive Care Unit. Indian J Crit Care Med 20(8):473-476, 2016

5. Kramer AA, Wijdicks EFM, Snavely VL, Dunivan JR, Naranjo LLS, Bible S, Rohs T, Dickess SM: A multicenter prospective study of interobserver agreement using the full outline of unresponsiveness score coma scale in the intensive care unit. Crit Care Med 40(9):2671-2676, 2012

6. McNett M, Amato S, Gianakis A, Grimm D, Philippbar SA Belle J, Moran C: The FOUR score and GCS as predictors of outcome after traumatic brain injury. Neurocrit Care 21:52-57, 2014

7. Okasha AS, Fayed AM, Saleh AS: The FOUR score predicts mortality, endotracheal intubation and ICU length of stay after traumatic brain injury. Neurocrit Care 21:496-504, 2014

8. Orken DN, Sagduyu AK, Sirin H, Isikara CT, Gokce M, Sutlas N, Ozturk S, Tarlaci S: Yeni bir koma değerlendirme ölçeği olan FOUR skorun Türkçe çevirisinin güvenirlik çalışması. Trakya Üniversitesi Tıp Fakültesi Dergisi 27(1):28-31, 2010

9. Sahin AS, Sahin M, Ozturk NK, Kizilates E, Karsli B: Comparision of GCS and FOUR scores in the evaluation of neurological status in intensive care unit. Journal of Contemporary Medicine 5(3):167-172, 2015

10. Temiz NC, Kose G, Tehli O, Acikel C, Hatipoglu S: A comparison between the effectiveness of full outline of unresponsiveness and Glasgow coma score at neurosurgical intensive care unit patients. Turk Neurosurg 28(2):248-250, 2018

11. Wijdicks EFM, Bamlet WR, Maramattom BV, Manno EM, McClelland RL: Validation of a new coma scale: The FOUR score. Ann Neurol 58:585-593, 2005

12. Wijdicks EFM, Rabinstein AA, Bamlet WR, Mandrekar JN: FOUR score and Glasgow Coma Scale in predicting outcome of comatose patients: A pooled analysis. Neurology 77(1):8485,2011 